\title{
Dietary patterns and survival of older Europeans: The EPIC-Elderly Study (European Prospective Investigation into Cancer and Nutrition)
}

Christina Bamia ${ }^{1}$, Dimitrios Trichopoulos ${ }^{2}$, Pietro Ferrari ${ }^{3}$, Kim Overvad ${ }^{4}$, Lone Bjerregaard $^{5}$, Anne Tiønneland ${ }^{6}$, Jytte Halkjær ${ }^{6}$, Françoise Clavel-Chapelon ${ }^{7}$, Emmanuelle Kesse ${ }^{8}$, Marie-Christine Boutron-Ruault ${ }^{7}$, Paolo Boffetta ${ }^{9}$, Gabriele Nagel ${ }^{10}$, Jacob Linseisen ${ }^{1}$, Heiner Boeing ${ }^{12}$, Kurt Hoffmann ${ }^{12}$, Christina Kasapa ${ }^{1}$, Anastasia Orfanou ${ }^{1}$, Chrysoula Travezea ${ }^{1}$, Nadia Slimani $^{3}$, Teresa Norat ${ }^{13}$, Domenico Palli ${ }^{14}$, Valeria Pala ${ }^{15}$, Salvatore Panico ${ }^{16}$, Rosario Tumino ${ }^{17}$, Carlotta Sacerdote $^{18}$, H Bas Bueno-de-Mesquita ${ }^{19}$, Patricia MCM Waijers ${ }^{19}$, Petra HM Peeters $^{20}$, Yvonne T van der Schouw ${ }^{20}$, Antonio Berenguer ${ }^{21}$, Carmen MartinezGarcia $^{22}$, Carmen Navarro ${ }^{23}$, Aurelio Barricarte ${ }^{24}$, Miren Dorronsoro ${ }^{25}$, Göran Berglund $^{26}$, Elisabet Wirfält ${ }^{26}$, Ingegerd Johansson ${ }^{27}$, Gerd Johansson ${ }^{28}$, Sheila Bingham ${ }^{29}$, Kay-Tee Khaw ${ }^{30}$, Elizabeth A Spencer ${ }^{31}$, Tim Key ${ }^{31}$, Elio Riboli ${ }^{3}$ and Antonia Trichopoulou ${ }^{1, *}$

'Department of Hygiene and Epidemiology, University of Athens, Medical School, 75 Mikras Asias Street, 11527 Athens, Greece: ${ }^{2}$ Department of Epidemiology, Harvard School of Public Health, Boston, MA, USA: ${ }^{3}$ Nutrition and Hormones Group, International Agency for Research on Cancer (IARC)-World Health Organization, Lyon, France: ${ }^{4}$ Department of Clinical Epidemiology, Aalborg Hospital, Aarhus University Hospital, Aarhus, Denmark: ${ }^{5}$ Cardiovascular Research Center, Department of Preventive Cardiology, Aalborg Hospital, Aarhus University Hospital, Aarhus, Denmark: 'Institute of Cancer Epidemiology, Danish Cancer Society, Copenhagen, Denmark: ${ }^{7}$ Equipe E3N-EPIC, INSERM, Institut Gustave Roussy, Paris, France: ${ }^{8}$ Institut Scientifique et Technique de la Nutrition et de l'Alimentation, Paris, France: ${ }^{9}$ Genetics and Epidemiology Cluster, IARC, Lyon, France: ${ }^{10}$ Department of Epidemiology, University of Ulm, Ulm, Germany: " 'Division of Clinical Epidemiology, German Cancer Research Center, Heidelberg, Germany: ${ }^{12}$ Department of Epidemiology, German Institute of Human Nutrition, PotsdamRehbrücke, Germany: ${ }^{13}$ Infections and Cancer Epidemiology Group, IARC, Lyon, France: ${ }^{14}$ Molecular and Nutritional Epidemiology Unit, CSPO-Scientific Institute of Tuscany, Florence, Italy: ${ }^{15}$ Epidemiology Unit, Istituto Nazionale per lo Studio e la Cura dei Tumori, Milan, Italy: ${ }^{16}$ Dipartimento di Medicina Clinica e Sperimentale, Federico II University, Naples, Italy: ${ }^{17}$ Cancer Registry, Azienda Ospedaliera 'Civile MP Arezzo', Ragusa, Italy: ${ }^{18}$ Unit of Cancer Epidemiology, Department of Biomedical Sciences and Human Oncology, University of Turin, Turin, Italy: ${ }^{19}$ Centre for Nutrition and Health, National Institute for Public Health and the Environment, Bilthoven, The Netherlands: ${ }^{20}$ Julius Center for Health Sciences and Primary Care, University Medical Center, Utrecht, The Netherlands: ${ }^{21}$ Department of Epidemiology, Catalan Institute of Oncology, Barcelona, Spain: ${ }^{22}$ Andalusian School of Public Health, Granada Cancer Registry, Granada, Spain: ${ }^{23}$ Epidemiology Department, Murcia Health Council, Murcia, Spain: ${ }^{24}$ Public Health Institute, Navarra, Spain: ${ }^{25}$ Department of Public Health of Gipuzkoa, Health Department of Basque Country, San Sebastian, Spain: ${ }^{26}$ Department of Medicine, Surgery and Orthopaedics, Lund University, Malmö, Sweden: ${ }^{27}$ Nutritional Research, Department of Public Health and Clinical Medicine \& Department of Odontology, Umeå University, Umeå, Sweden: ${ }^{28}$ Nutritional Research, Department of Public Health and Clinical Medicine, Umeå University, Umeå, Sweden: ${ }^{29}$ MRC Dunn Human Nutrition Unit, Cambridge, UK: ${ }^{30}$ Institute of Public Health, University of Cambridge, Cambridge, UK: ${ }^{31}$ Cancer Research UK Epidemiology Unit, Oxford University, Oxford, UK

Submitted 17 February 2006: Accepted 4 July 2006: First published online 5 March 2007

\section{Abstract}

Objective: To investigate the association of a posteriori dietary patterns with overall survival of older Europeans.

Design and setting: This is a multi-centre cohort study. Cox regression analysis was used to investigate the association of the prevailing, a posteriori-derived, plant-based dietary pattern with all-cause mortality in a population of subjects who were 60 years
} 
or older at recruitment to the European Prospective Investigation into Cancer and Nutrition (EPIC-Elderly cohort). Analyses controlled for all known potential risk factors.

Subjects: In total, 74607 men and women, 60 years or older at enrolment and without previous coronary heart disease, stroke or cancer, with complete information about dietary intakes and potentially confounding variables, and with known survival status as of December 2003, were included in the analysis.

Results: An increase in the score which measures the adherence to the plant-based diet was associated with a lower overall mortality, a one standard deviation increment corresponding to a statistically significant reduction of 14\% (95\% confidence interval 5-23\%). In country-specific analyses the apparent association was stronger in Greece, Spain, Denmark and The Netherlands, and absent in the UK and Germany.

Conclusions: Greater adherence to the plant-based diet that was defined a posteriori in this population of European elders is associated with lower all-cause mortality. This dietary score is moderately positively correlated with the Modified Mediterranean Diet Score that has been constructed $a$ priori and was also shown to be beneficial for the survival of the same EPIC-Elderly cohort.

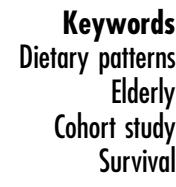

Dietary patterns have attracted considerable interest in nutritional epidemiology for assessing the impact of dietary intakes on the risk of several diseases and mortality ${ }^{1,2}$. Assessing diet by dietary patterns rather than by selected nutrients or foods has the advantage of capturing the high inter-correlation of nutrients and foods within a diet, as well as integrating complex interactive effects of many dietary exposures ${ }^{3,4}$. In this context, dietary patterns and their association with longevity have been studied for the elderly, an age group that is gradually increasing in most developed countries ${ }^{5-13}$.

Two general approaches have been used to define dietary patterns. The 'a priori approach' focuses on the construction of patterns that reflect hypothesis-oriented combinations of foods and nutrients ${ }^{14}$. These patterns are operationalised through the calculation of a graded score which identifies groups with 'better' or 'worse' nutritional intakes. A priori scores that have been used in the literature are based either on dietary recommendations $^{6,15-18}$ or on previous knowledge concerning the favourable or adverse health effects of various dietary constituents $5,12,13,19-21$.

The second approach builds on exploratory statistical methods - usually principal components and factor analyses - and uses the observed dietary data in order to extract dietary patterns a posteriori. The 'a posteriori approach' has been used in nutritional studies either of a descriptive nature ${ }^{22-28}$ or in relation to a particular health outcome $8,20,29-37$. The a posteriori approach is considered a useful tool for identifying the prevailing dietary habits of a particular study population ${ }^{4}$. Although this procedure is promising in summarising diet or certain combinations of foods, its utility in investigating associations of diet and disease is debatable because the extracted dietary patterns may have little relation to disease or mortality if, for example, nutrients or foods relevant to the aetiology of specific diseases are not incorporated in their definition ${ }^{20}$. In addition, a posteriori patterns identified in one study population may not be reproduced in other study populations $^{4,38}$.

We have previously evaluated the effect of an a priori dietary pattern on survival in a large, multi-centre cohort of elders living in nine different European countries - The EPIC-Elderly Study (European Prospective Investigation into Cancer and Nutrition) ${ }^{13}$. In the present paper we investigate the association with survival of an a posteriori dietary pattern, extracted from this multi-centre population as reported previously ${ }^{27}$.

\section{Methods}

\section{Recruitment}

The EPIC-Elderly project aimed to identify the prevailing dietary patterns across European elders and examine their association with overall mortality. The cohort includes individuals who were 60 years or older at recruitment and participated in the EPIC study. EPIC is a multi-centre cohort study examining the role of diet on the aetiology of cancer and other chronic diseases, under the coordination of the International Agency for Research on Cancer (IARC). Details on the design, sample selection and methodology of the EPIC study have been described in detail elsewhere ${ }^{39,40}$, In brief, between 1992 and 2000, 519978 apparently healthy volunteers were recruited in EPIC from 23 centres in 10 European countries (Denmark, France, Germany, Greece, Italy, The Netherlands, Norway, Spain, Sweden and the UK). Centre-specific cohorts consisted, in general, of subjects who agreed to participate and were recruited from populations living in various regions. In France, Norway, Utrecht (The Netherlands) and Naples (Italy) only females were enrolled. The study protocol has been approved by ethical committees at both IARC and the participating centres. All participants signed an informed consent form before enrolment. All procedures have been in line with the Helsinki Declaration on Human Rights. 
Data for 100442 participants from all countries are included in the EPIC-Elderly database with the exception of Norway, where the cohort is relatively young (all of the Norwegians in the EPIC cohort were younger than 60 years at enrolment).

\section{Dietary intakes}

Information on foods and beverages consumed during the year preceding enrolment was collected with the use of instruments that had been developed and validated within each centre ${ }^{41}$. The dietary questionnaires were, in general, food-frequency questionnaires (FFQs) that were developed in a common way with deviations aiming at capturing the unique characteristics of diets followed in each participating centre/country.

The results presented in this paper are based on overall dietary intakes (in $\mathrm{g} \mathrm{day}^{-1}$ ) obtained from the FFQs and calculated taking into account standard recipes and edible fractions. Alcohol consumption was expressed in gethanolday ${ }^{-1}$. Total energy intake (in $\mathrm{kJday}^{-1}$ ) for each participant was also estimated.

\section{The a posteriori dietary pattern}

Principal component analysis (PCA) using the correlation matrix was performed on residuals from linear regressions of each of 22 food groups (vegetables, fruits, potatoes, legumes, pasta/rice/other grains, bread, other cereals, cakes, sugar \& confectionery, vegetable oils, margarine, butter, dairy products, meat \& products, eggs, fish \& shellfish, non-alcoholic beverages, wine, other alcoholic beverages, condiments \& sauces, soups and soy) on total energy intake, in order to control for the role of energy intake on the reported individual food intakes ${ }^{42}$. The retained a posteriori dietary patterns were labelled on the basis of food groups, the consumption of which produced high positive scores in the respective principal component. A detailed list of the food groups and the food items contained in them, as well as results from this work, has been reported elsewhere ${ }^{27}$.

The most important a posteriori dietary pattern, which was labelled 'plant-based', was defined by the first principal component and explained $14.6 \%$ of the total variation. This procedure-derived pattern was expressed through a score, estimated as a weighted linear combination of intakes of vegetables (positive coefficient), vegetable oils (positive coefficient), fruit (positive coefficient), pasta/rice/other grains (positive coefficient), legumes (positive coefficient), potatoes (negative coefficient), margarine (negative coefficient) and non-alcoholic beverages (negative coefficient). Hence, high plant-based dietary scores denote a diet rich in plant foods such as vegetables and vegetable oils, fruit, pasta/rice/other grains and legumes, but poor in potatoes, margarine and nonalcoholic beverages. Naturally, low scores imply the opposite pattern of consumption. The plant-based dietary pattern was used as the a posteriori dietary exposure in the present study.

\section{Lifestyle, antbropometric and medical variables}

Data on a number of lifestyle and health variables were recorded with the use of a core lifestyle questionnaire, which contained a common set of questions and possible answers, for all participating centres. The lifestyle questionnaire included questions on educational achievement, history of previous illnesses, history of smoking, and physical activity at recruitment (at occupation and during leisure). For leisure, time spent on each of a number of activities (in hours per week) was multiplied by an energy cost coefficient to convert hours per week into $\mathrm{kJ}^{43}$; all products were then summed to produce a score of daily physical activity at leisure expressed in gender- and centre-specific tertiles.

Anthropometric measurements (height, weight, waist and hip circumferences) were taken in all EPIC centres using similar standardised procedures, except for France, Oxford and Norway. In the latter centres self-reported values were recorded instead, with actual measurements being obtained for a fraction of the participants. Body mass index (BMI) was calculated as the ratio of weight in kilograms divided by the square of height in metres; for participants with self-reported weight and height, these values were used in the respective calculations.

\section{Follow-up}

Information on vital status of EPIC participants was obtained by population mortality registries (at the national or regional level), as well as by active follow-up.

As of December 2003, vital status had been ascertained for 100309 of the 100442 participants with acceptable reports of dietary energy intakes (i.e. excluding over- and underreporters with intakes within the top and bottom 1\% of the ratio of energy intake to estimated energy requirement). A further 15362 subjects were excluded because at enrolment they had been diagnosed with coronary heart disease, stroke or cancer. In addition, 10340 subjects had missing information for one or more of the dietary anthropometric or lifestyle variables, or had died within the first year after enrolment. Thus, 74607 individuals were included in this study.

\section{Statistical analysis}

Analyses were carried out with Stata 8.0 (StataCorp). Descriptive presentation relied on cross-tabulations using overall tertiles of the plant-based dietary score. Survival data were modelled through Cox proportional hazards regression models, which assessed the association between the plant-based dietary pattern and overall mortality. The associations were investigated by estimating the adjusted mortality rate ratio by tertile of the plantbased dietary score, as well as in relation to an increment of one standard deviation (1SD) (1.84 units). For analyses 
by country, country-specific tertiles of the plant-based dietary score were used. In all models, ethanol intake which did not contribute to the derivation of the principal component under consideration - was also included as a categorical variable $\left(<10 \mathrm{~g} \mathrm{day}^{-1}, 10-20 \mathrm{~g} \mathrm{day}^{-1},>20\right.$ $\mathrm{g} \mathrm{day}^{-1}$ ) in order to take into account the reported Ushaped association of alcohol with mortality from coronary heart disease ${ }^{44,45}$.

Adjustment was performed for sex, age, self-reported diabetes mellitus at enrolment, educational achievement, smoking status, physical activity at recruitment (occupation and leisure-time), waist-to-hip ratio (WHR), BMI and total energy intake. The proportionality assumption was checked with the log-log plots. No time-dependent variables were included in the Cox models. Both fixedand random-effects models were calculated, the latter in order to accommodate between-country variation in the estimated effects.

In all models, subjects who were alive as of the date of last follow-up or had emigrated to another region or country or were lost from follow-up were considered as censored as of the date of last contact, whereas the focal event was death from any cause. Separate proportional hazard models were performed for all 74607 subjects as well as for participants in each country. Proportional hazard models were stratified by country (for analysis of the total EPIC-Elderly cohort) or by centre (for the country-specific analyses) to account for different methods of follow-up and questionnaires used for data collection. In all analyses a 5\% statistical level of significance was used.

\section{Results}

The distribution of the 74607 study participants by country, sex and age at enrolment has been reported elsewhere $^{13}$. There were, in general, more women than men in the cohort and distributions by age varied by country. Calculated mean energy intake ranged from
$8157 \mathrm{~kJ} \mathrm{day}^{-1}$ in Umeå (Sweden) to $11188 \mathrm{~kJ} \mathrm{day}^{-1}$ in San Sebastian (Spain) for males, and from 5958 to $9450 \mathrm{~kJ} \mathrm{day}^{-1}$ for females of the Umeå (Sweden) and Naples (Italy) centres, respectively.

Table 1 shows the distribution of 74607 participants and 4047 deaths in the EPIC-Elderly cohort, by country and overall tertile of the plant-based diet. The percentages of individuals falling into the different tertiles of this dietary pattern vary markedly across countries. Subjects in Greece, Italy, Spain, and to a lesser extent France, are highly in favour of this dietary pattern since their scores belong generally to the third tertile of the score. In contrast, most people in Sweden and Denmark have low scores, indicating that their diets consist of potatoes, margarine and non-alcoholic beverages rather than vegetables, vegetable oils, legumes, fruit and pasta/rice/ other grains. In the UK, Germany and The Netherlands, the highest proportion of individuals belong to the second tertile, i.e. they do not consume many of the aboveindicated food groups that contribute to this pattern with either positive or negative scoring coefficients. Regarding number of deaths, there was a negative trend, both overall and within most countries, in the proportion of deaths with increasing tertile of the score.

Table 2 shows the mean intakes of food groups by tertile of the plant-based dietary pattern. The food groups shown in this table are the food groups that were originally used to extract dietary patterns in the EPIC-Elderly cohort ${ }^{27}$. As expected, there is a clear, positive trend across tertiles of this pattern in the mean intakes of food groups which had positive scoring coefficients (vegetables, legumes, fruit, pasta/rice/other grains and vegetable oils) and a negative trend regarding consumption of potatoes, margarine and non-alcoholic beverages (food groups with negative scoring coefficients). Regarding the consumption of food groups not included in the principal component score, only that of wine is steadily increasing from the first to the third tertile. The consumption of bread, fish \& shellfish and eggs does not vary greatly whereas there is an inverse

Table 1 Distribution of 74607 participants and 4047 deaths of the EPIC-Elderly cohort, by country and tertile of the plant-based dietary score. The EPIC-Elderly Study (European Prospective Investigation into Cancer and Nutrition)

\begin{tabular}{|c|c|c|c|c|c|c|c|c|c|c|c|c|}
\hline \multirow[b]{4}{*}{ Country } & \multicolumn{12}{|c|}{ Plant-based dietary pattern } \\
\hline & \multicolumn{6}{|c|}{ Distribution of participants } & \multicolumn{6}{|c|}{ Distribution of deaths } \\
\hline & \multicolumn{2}{|c|}{ 1st tertile } & \multicolumn{2}{|c|}{ 2nd tertile } & \multicolumn{2}{|c|}{ 3rd tertile } & \multicolumn{2}{|c|}{ 1st tertile } & \multicolumn{2}{|c|}{ 2nd tertile } & \multicolumn{2}{|c|}{ 3rd tertile } \\
\hline & $n$ & $\%$ & $n$ & $\%$ & $n$ & $\%$ & $n$ & $\%$ & $n$ & $\%$ & $n$ & $\%$ \\
\hline Denmark & 6462 & 51 & 5828 & 46 & 399 & 3 & 524 & 8.1 & 349 & 6.0 & 21 & 5.3 \\
\hline France & 122 & 1 & 3349 & 35 & 6059 & 64 & 6 & 4.9 & 110 & 3.9 & 186 & 3.1 \\
\hline Germany & 3221 & 43 & 4165 & 55 & 169 & 2 & 116 & 3.6 & 130 & 3.1 & 7 & 4.1 \\
\hline Greece & 0 & 0 & 16 & 0 & 7363 & 100 & 0 & 0 & 1 & 6.3 & 236 & 3.2 \\
\hline Italy & 3 & 0 & 135 & 3 & 5255 & 97 & 0 & 0 & 6 & 4.4 & 147 & 2.8 \\
\hline Netherlands & 1892 & 34 & 3484 & 62 & 224 & 4 & 121 & 6.4 & 155 & 4.5 & 8 & 3.6 \\
\hline Spain & 0 & 0 & 126 & 3 & 3727 & 97 & 0 & 0 & 7 & 5.6 & 129 & 3.5 \\
\hline Sweden & 9121 & 77 & 2612 & 22 & 121 & 1 & 640 & 7.0 & 144 & 5.5 & 5 & 4.1 \\
\hline UK & 4048 & 38 & 5154 & 48 & 1552 & 14 & 463 & 11.4 & 431 & 8.4 & 105 & 6.8 \\
\hline Total & 24869 & 33.3 & 24869 & 33.3 & 24869 & 33.3 & 1870 & 7.5 & 1333 & 5.4 & 844 & 3.4 \\
\hline
\end{tabular}


Table 2 Mean daily intakes of selected food groups and associated standard deviations (SD) by tertile of the plant-based dietary score. The EPIC-Elderly Study (European Prospective Investigation into Cancer and Nutrition)

\begin{tabular}{|c|c|c|c|c|c|c|}
\hline \multirow[b]{3}{*}{ Food group } & \multicolumn{6}{|c|}{ Plant-based dietary score } \\
\hline & \multicolumn{2}{|c|}{ 1st tertile } & \multicolumn{2}{|c|}{ 2nd tertile } & \multicolumn{2}{|c|}{ 3rd tertile } \\
\hline & Mean $(g)$ & SD (g) & Mean $(\mathrm{g})$ & $\mathrm{SD}(\mathrm{g})$ & Mean $(g)$ & $\mathrm{SD}(\mathrm{g})$ \\
\hline Vegetables & 134.62 & 80.21 & 194.46 & 105.26 & 307.00 & 173.16 \\
\hline Legumes & 4.05 & 8.56 & 7.53 & 11.83 & 22.01 & 26.38 \\
\hline Fruit & 159.83 & 102.03 & 234.73 & 139.11 & 399.39 & 229.00 \\
\hline Pasta/rice/other grains & 20.75 & 21.30 & 36.41 & 31.53 & 86.65 & 66.75 \\
\hline Bread & 123.18 & 64.61 & 120.85 & 67.11 & 129.95 & 79.26 \\
\hline Other cereal & 44.80 & 80.26 & 25.90 & 44.90 & 11.56 & 26.28 \\
\hline Vegetable oils & 1.61 & 2.68 & 2.96 & 3.62 & 25.09 & 19.53 \\
\hline Fish \& shellfish & 37.04 & 30.63 & 34.58 & 29.52 & 35.98 & 32.06 \\
\hline Dairy products & 416.78 & 269.21 & 342.24 & 222.63 & 260.45 & 182.01 \\
\hline Meat \& products & 109.29 & 56.32 & 95.65 & 54.15 & 87.74 & 50.97 \\
\hline Potatoes & 149.96 & 91.88 & 97.21 & 57.36 & 55.17 & 45.15 \\
\hline Margarine & 20.31 & 22.14 & 8.60 & 11.64 & 2.52 & 5.70 \\
\hline Butter & 3.71 & 9.74 & 4.43 & 8.33 & 2.30 & 5.56 \\
\hline Cakes & 54.86 & 52.68 & 39.84 & 39.08 & 27.57 & 31.75 \\
\hline Sugar \& confectionery & 50.65 & 39.70 & 36.18 & 27.84 & 27.65 & 25.33 \\
\hline Condiments \& sauces & 24.24 & 24.74 & 18.80 & 17.15 & 16.48 & 15.35 \\
\hline Non-alcoholic beverages & 1488.51 & 707.77 & 1342.19 & 598.38 & 551.70 & 591.48 \\
\hline Wine & 32.56 & 58.67 & 70.67 & 110.36 & 98.31 & 165.25 \\
\hline Other alcoholic beverages & 167.63 & 325.40 & 91.47 & 185.48 & 31.84 & 102.18 \\
\hline Eggs & 17.69 & 17.87 & 16.69 & 17.06 & 16.81 & 16.80 \\
\hline Total energy intake ( $\mathrm{kJ}$ day $^{-1}$ ) & 9070.38 & 2538.79 & 8142.20 & 2303.78 & 8569.14 & 2476.25 \\
\hline
\end{tabular}

trend in the consumption of other cereals, meat \& products, dairy products, butter, cakes, sugar \& confectionery, condiments \& sauces and alcoholic beverages (except wine) across tertiles of the plant-based dietary score. With respect to energy intake, subjects in the second tertile seem to have a lower energy intake than subjects who either follow (third tertile) or do not follow (first tertile) the plant-based diet.

Table 3 shows the association of the plant-based diet with overall mortality, after adjustment for potential confounders, overall (using global tertiles) and by country (using country-specific tertiles). There is evidence that an increase in the plant-based dietary score is associated with reduced overall mortality, with a $1 \mathrm{SD}$ increment corresponding to a statistically significant $14 \%$ reduction in allcause mortality (random-effects model). Subjects whose scores belong to the second (mean plant-based dietary score -0.5 , SD 0.4 ) or third (mean plant-based dietary score 2.2 , SD 1.4) tertile of this pattern have a $10 \%$ and $11 \%$ reduced mortality rate, respectively, compared with those who belong to the first tertile (mean plant-based dietary score -1.7 , SD 0.6). Results in this table indicate that subjects with greater consumption of a diet rich in plant foods and vegetable oils and poor in potatoes, margarine and non-alcoholic beverages have substantially reduced mortality compared with those who follow the opposite pattern of consumption.

There was some evidence of heterogeneity in the apparent effect among countries, the association being stronger in Greece, Spain, Denmark and The Netherlands, and absent in the UK and Germany. Nevertheless, this heterogeneity is accommodated through the randomeffects model. It should be noted that the mortality ratios for the second and third country-specific tertiles of the plant-based dietary score are not comparable between countries since the referent category (first tertile) varies across countries.

\section{Discussion}

In the present prospective study of apparently healthy elderly Europeans, we found that an a posteriori dietary pattern, predominantly reflecting high intakes of vegetables, vegetable oils, fruit, legumes and pasta/rice/other grains and low intakes of potatoes, margarine and nonalcoholic beverages, may be associated with a longer life expectancy, after adjusting for relevant confounders. The chosen plant-based dietary pattern has been identified as prevailing in a previous descriptive analysis in the EPICElderly cohort ${ }^{27}$ by means of PCA. The dietary characteristic of this pattern is that it relies on plant foods and vegetable oils for which inverse associations with the risk of disease and/or death have been reported ${ }^{42,46}$. In addition, increasing plant-based dietary scores were accompanied with a reduction in the intakes of food groups of which high consumption may be considered non-beneficial, such as meat and dairy products ${ }^{31,47,48}$. In this context, the protective effect of an increasing score in the evaluated principal component is compatible with the 
Table 3 Fully adjusted* mortality ratio (95\% confidence interval) by category and one standard deviation (1SD) increment of the plant-based dietary score. The EPIC-Elderly Study (European Prospective Investigation into Cancer and Nutrition)

\begin{tabular}{lccc}
\hline & \multicolumn{3}{c}{ Plant-based dietary score } \\
\cline { 2 - 4 } & 2nd tertile & 3rd tertile & 1SD increment (overall) \\
\hline $\begin{array}{l}\text { Over all countriest } \\
\text { Fixed effects }\end{array}$ & $0.93(0.86-1.00)$ & $0.92(0.79-1.06)$ & $0.90(0.85-0.96)$ \\
Random effects & $0.90(0.84-0.98)$ & $0.89(0.79-0.99)$ & $0.86(0.77-0.95)$ \\
$P$-value for heterogeneity & 0.502 & 0.124 & 0.06 \\
Analyses by countrył & & & \\
Denmark & $0.92(0.78-1.07)$ & $0.85(0.72-1.01)$ & $0.85(0.72-1.01)$ \\
France & $0.89(0.67-1.17)$ & $0.95(0.71-1.28)$ & $0.89(0.68-1.16)$ \\
Germany & $0.97(0.71-1.32)$ & $1.08(0.79-1.48)$ & $1.25(0.85-1.82)$ \\
Greece & $0.72(0.52-0.99)$ & $0.55(0.36-0.85)$ & $0.67(0.50-0.89)$ \\
Italy & $1.01(0.67-1.52)$ & $0.93(0.56-1.55)$ & $0.83(0.61-1.15)$ \\
Netherlands & $0.81(0.61-1.07)$ & $0.70(0.52-0.96)$ & $0.55(0.37-0.82)$ \\
Spain & $0.67(0.42-1.07)$ & $0.71(0.43-1.18)$ & $0.83(0.61-1.12)$ \\
Sweden & $1.04(0.87-1.24)$ & $0.95(0.78-1.15)$ & $0.91(0.76-1.08)$ \\
UK & $0.88(0.75-1.02)$ & $1.03(0.86-1.22)$ & $0.97(0.86-1.10)$ \\
\hline
\end{tabular}

*Adjusted for sex (men, women), age (60-64 years, 65-69 years, 70-74 years, >75 years), diagnosis of diabetes mellitus at baseline (yes, no), waist-to-hip ratio (in ordered quintiles), body mass index (in ordered quintiles), educational achievement (none/primary school, technical school, secondary school, university degree), smoking status (never, former and four categories of current smoker: 1-10 cigarettes day ${ }^{-1}, 11-20$ cigarettes day $^{-1}, 21-30$ cigarettes day $^{-1}$, $>31$ cigarettes day ${ }^{-1}$, considered as an ordered variable), physical activity at current work (retired or sedentary occupation, standing occupation, manual work, heavy manual work), physical activity score at leisure time (in centre- and sex-specific tertiles, categorically), ethanol intake ( $\left.<10 \mathrm{~g} \mathrm{day}^{-1}, 10-20 \mathrm{~g} \mathrm{day}^{-1},>20 \mathrm{~g} \mathrm{day}^{-1}\right)$ and total energy intake (in ordered quintiles).

† Stratified by country.

$\ddagger$ Country-specific tertiles of the plant-based diet score were used in the country-specific analyses.

I Stratified by centre within country,

empirical evidence concerning the foods and the loading factors contributing to this component.

The EPIC-Elderly study comprises data from the largest existing database set up to investigate the role of diet on the longevity of older people. Previous analysis of data from this study has resulted in recommending an a priori dietary pattern, the Modified Mediterranean Diet Score (MMDS), as conducive to survival ${ }^{13}$. The effect of MMDS on survival of the EPIC-Elderly cohort was comparable to that of the extracted main principal component. Nevertheless, the overall correlation between MMDS and the plant-based dietary score was only 0.621 , indicating that the MMDS and the main principal component extracted from the foods consumed by the study participants capture partially (but not fully) overlapping beneficial aspects of diet.

Recently a priori scores have gained popularity in the scientific community ${ }^{12,19,49,50}$, possibly because they identify a desirable pattern, adherence to which could maximise health benefits. A posteriori scores, on the other hand, frequently assessed in conjunction with cluster analysis, point to patterns that are spontaneously developed in particular populations on the basis of intercorrelations among food groups. In a sense a posteriori scores trace existing patterns whereas a priori scores target nutritional objectives variously defined. In any case both $a$ priori and a posteriori scores should be studied, and the convergence of the inferences drawn from their relationships to health indicators can circumscribe the space where an optimal diet may be identified.
The a posteriori plant-based dietary score was a strong indicator of the participating countries in the population of EPIC elders - all countries in the Mediterranean region belong generally to its third tertile whilst elders in Central and Northern Europe belong to the first and second tertiles of the respective score. Whilst this may raise concern about the effect of the plant-based diet on survival being largely ecological, this cannot be the case when countryspecific analyses were performed, since country-specific tertiles were used. Our results also suggest that although intakes of the various food groups within country-specific tertiles may differ substantially between countries, a consumption pattern with stronger resemblance to the plant-based pattern is beneficial, regardless of the exact levels of intake.

Results from our study are in agreement with those from previous studies of the elderly which have identified $a$ posteriori dietary patterns and investigated their association with biomarkers, morbidity and mortality. Kumagai and colleagues ${ }^{8}$ found an inverse association between a plant-food pattern score and overall mortality of elderly Japanese. In The Netherlands, Huijbregts and colleagues ${ }^{51}$ used cluster analysis and identified a 'healthful' cluster with lower cardiovascular risk factors. Studies in the USA also showed a benefit from healthy eating patterns derived by cluster analyses on bone mineral density ${ }^{52}$ and cardiovascular events ${ }^{53}$.

Although a posteriori-derived dietary patterns have great intuitive appeal in nutritional epidemiology because they can summarise dietary habits of a population, their 
use in examining diet-disease relationships remains controversial mainly because the identification of these patterns depends strongly on the statistical methodology that is used ${ }^{42}$. Specifically, PCA aims at maximising the fraction of variance explained by a weighted linear combination of original variables; this, however, does not necessarily increase the ability to discriminate between deceased and not deceased subjects. In addition, $a$ posteriori dietary patterns have interpretability problems since their definition is not based on previous evidence or dietary recommendations. Our plant-based dietary pattern was relatively easy to interpret and its elements turned out to be part of 'healthy' or 'prudent' dietary patterns in several studies among the elderly ${ }^{8,28,51-53}$ as well as among other populations $22,30,32,52$.

Advantages of this study include its prospective nature, its large size and its reliance on a European population of subjects aged 60 years or older. This study allowed control for several non-dietary confounders such as education and physical activity, as well as anthropometry such as BMI and WHR. However, residual confounding cannot be entirely ruled out because of the observational study design. It has been argued that observed dietary patterns are part of specific lifestyles ${ }^{38}$. Whilst this may strengthen the usefulness of the a posteriori approach to describe diet, it may also mean that it is difficult to separate the effects of the extracted pattern from the effects of other lifestyle characteristics ${ }^{54}$.

In conclusion, our study suggests that greater adherence to a diet, defined a posteriori in the overall population of European elders and relying on intakes of plant foods and avoidance of margarine, non-alcoholic beverages and potatoes, is associated with lower all-cause mortality. This dietary pattern is moderately positively correlated with the MMDS that has been constructed a priori and was also shown to be beneficial for the survival of the same EPICElderly cohort $^{13}$.

\section{Acknowledgements}

Sources offunding: This study was supported by the 'Quality of Life and Management of Living Resources' Programme of the European Commission (DG Research, contract no. QLK6-CT-2001-00 241) for the project EPIC-Elderly, coordinated by the Department of Hygiene and Epidemiology, University of Athens Medical School; the 'Europe against Cancer' Programme of the European Commission (DG SANCO) for the project EPIC coordinated by the International Agency for Research on Cancer (World Health Organization); Greek Ministry of Health and the Greek Ministry of Education (Greece); a fellowship honouring Vasilios and Nafsika Tricha (Greece); The Danish Cancer Society (Denmark); Ligue contre le Cancer (France); Société 3M (France); Mutuelle Générale de l'Education Nationale (France); Institut National de la Santé et de la Recherche Médicale (INSERM) (France); Gustave Roussy Institute and several General Councils in France (France); German Cancer Aid (Germany); German Cancer Research Center (Germany); German Federal Ministry of Education and Research (Germany); EPIC Italy is supported by a generous grant from the Associazione Italiana per la Ricerca sul Cancro (AIRC, Milan); Associazione Italiana per la Ricerca contro il Cancro (AIRC) in Florence (Italy); Compagnia di San Paolo (Italy); Regione Sicilia, Associazione Italiana Ricerca Cancro and Avis-Ragusa (Italy); Dutch Ministry of Public Health, Welfare and Sports (The Netherlands); Health Research Fund (FIS) of the Spanish Ministry of Health (Spain); the Spanish Regional Governments of Andalucia, Asturias, Basque Country, Murcia and Navarra (Spain); the ISCIII Network Red de Centros RCESP (C03/09) (Spain); Swedish Cancer Society (Sweden); Swedish Scientific Council, City of Malmö (Sweden); Regional Government of Skåne (Sweden); Cancer Research UK (UK); Medical Research Council (UK).

The funding sources had no involvement in the study design, in the collection, analysis and interpretation of data, in the writing of the report and in the decision to submit the paper for publication. The author(s) is (are) solely responsible for the publication and the publication does not represent the opinion of the Community. The Community is not responsible for any use that might be made of data appearing in this work.

Conflict of interest declaration: None of the authors has declared any competing interest. All authors accept the conditions laid down in the Notes for Authors. The paper has not been submitted for consideration elsewhere.

Authorship responsibilities: Christina Bamia is the principal biostatistician in this project. Antonia Trichopoulou is the principal investigator of the EPIC-Elderly project. She is guarantor for the paper. Contributors from the participating centres provided the original data, information on the respective populations, and advice on study design and analysis. Participants from the International Agency for Research on Cancer were responsible for coordination of the overall EPIC project and also contributed advice on study design and analysis. All authors have seen and approved the manuscript.

\section{References}

1 Carlson JJ, Monti V. The role of inclusive dietary patterns for achieving secondary prevention cardiovascular nutrition guidelines and optimal cardiovascular health. Journal of Cardiopulmonary Rebabilitation 2003; 23: 322-33.

2 Kant AK. Dietary patterns and health outcomes. Journal of the American Dietetic Association 2004; 104: 615-35.

3 Gordon T, Fisher M, Rifkind BM. Some difficulties inherent in the interpretation of dietary data from free-living populations. American Journal of Clinical Nutrition 1984; 39: $152-6$.

4 Jacques PF, Tucker KL. Are dietary patterns useful for understanding the role of diet in chronic disease? American Journal of Clinical Nutrition 2001; 73: 1-2.

5 Trichopoulou A, Kouris-Blazos A, Wahlqvist ML, Gnardellis C, Lagiou P, Polychronopoulos E, et al. Diet and 
overall survival in elderly people. British Medical Journal 1995; 311: 1457-60.

6 Huijbregts P, Feskens E, Rasanen L, Fidanza F, Nissinen A, Menotti A, et al. Dietary pattern and 20 year mortality in elderly men in Finland, Italy, and the Netherlands: longitudinal cohort study. British Medical Journal 1997; 315: 13-7.

7 Osler M, Schroll M. Diet and mortality in a cohort of elderly people in a north European Community. International Journal of Epidemiology 1997; 26: 155-9.

8 Kumagai S, Shibata H, Watanabe S, Suzuki T, Haga H. Effect of food intake pattern on all-cause mortality in the community elderly: a 7-year longitudinal study. Journal of Nutrition, Health \& Aging 1999; 3: 29-33.

9 Kouris-Blazos A, Gnardellis C, Wahlqvist ML, Trichopoulos D, Lukito W, Trichopoulou A. Are the advantages of the Mediterranean diet transferable to other populations? A cohort study in Melbourne, Australia. British Journal of Nutrition 1999; 82: 57-61.

10 Lasheras C, Fernandez S, Patterson AM. Mediterranean diet and age with respect to overall survival in institutionalised, nonsmoking elderly people. American Journal of Clinical Nutrition 2000; 71: 987-92.

11 Shimizu K, Takeda S, Noji H, Hirose N, Ebihara Y, Arai Y, et al. Dietary patterns and further survival in Japanese centenarians. Journal of Nutritional Science and Vitaminology 2003; 49: 133-8.

12 Knoops KT, de Groot LC, Kromhout D, Perrin AE, MoreirasVarela O, Menotti A, et al. Mediterranean diet, lifestyle factors, and 10-year mortality in elderly European men and women: the HALE project. Journal of the American Medical Association 2004; 92: 1433-9.

13 Trichopoulou A, Orfanos P, Norat T, Bueno-de-Mesquita B, Ocke MC, Peeters PH, et al. Modified Mediterranean diet and survival: The EPIC-Elderly study. British Medical Journal 2005; 330: 991.

14 Trichopoulos D, Lagiou P. Dietary patterns and mortality. British Journal of Nutrition 2001; 85: 133-4.

15 Patterson RE, Haines PS, Popkin BM. Diet quality index: capturing a multidimensional behavior. Journal of the American Dietetic Association 1994; 94: 57-64.

16 Kennedy ET, Ohls J, Carlson S, Fleming K. The Healthy Eating Index: design and applications. Journal of the American Dietetic Association 1995; 95: 1103-8.

17 Haines PS, Siega-Riz AM, Popkin BM. The Diet Quality Index revised: a measurement instrument for populations. Journal of the American Dietetic Association 1999; 99: 697-704.

18 McCullough ML, Feskanich D, Stampfer MJ, Giovannucci EL, Rimm EB, Hu FB, et al. Diet quality and major chronic disease risk in men and women: moving toward improved dietary guidance. American Journal of Clinical Nutrition 2002; 76: 1261-71.

19 Trichopoulou A, Costacou T, Bamia C, Trichopoulos D. Adherence to Mediterranean diet and survival in a Greek population. New England Journal of Medicine 2003; 348: 2599S-608S.

20 Schulze MB, Hoffmann K, Kroke A, Boeing H. Risk of hypertension among women in the EPIC-Potsdam Study: comparison of relative risk estimates for exploratory and hypothesis-oriented dietary patterns. American Journal of Epidemiology 2003; 158: 365-73.

21 Trichopoulou A, Bamia C, Trichopoulos D. Mediterranean diet and survival among patients with coronary heart disease in Greece. Archives of Internal Medicine 2005; 165: 929-35.

22 Prevost AT, Whichelow MJ, Cox BD. Longitudinal dietary changes between 1984-5 and 1991-2 in British adults: association with socio-demographic, lifestyle and health factors. British Journal of Nutrition 1997; 78: 873-88.
23 Schulze MB, Hoffmann K, Kroke A, Boeing H. Dietary patterns and their association with food and nutrient intake in the European Prospective Investigation into Cancer and Nutrition (EPIC)-Postdam Study. British Journal of Nutrition 2001; 85: 363-73.

24 McCann SE, Weiner J, Graham S, Freudenheim JL. Is principal components analysis necessary to characterise dietary behaviour in studies of diet and disease? Public Health Nutrition 2001; 4: 903-8.

25 Balder HF, Virtanen M, Brants HA, Krogh V, Dixon LB, Tan F, et al. Common and country-specific dietary patterns in four European cohort studies. Journal of Nutrition 2003; 133: 4246-51.

26 Costacou T, Bamia C, Ferrari P, Riboli E, Trichopoulos D, Trichopoulou A. Tracing the Mediterranean diet through principal components and cluster analyses in the Greek population. European Journal of Clinical Nutrition 2003; 57: $1378-85$.

27 Bamia C, Orfanos P, Ferrari P, Overvad K, Hundborg HH, Tjonneland A, et al. Dietary patterns among older Europeans: the EPIC-Elderly study. British Journal of Nutrition 2005; 94: 100-13.

28 Pala V, Sieri S, Masala G, Palli D, Panico S, Vineis P, et al. Associations between dietary pattern and lifestyle, anthropometry and other health indicators in the elderly participants of the EPIC-Italy cohort. Nutrition, Metabolism, and Cardiovascular Diseases 2006; 16: 186-201.

29 Whichelow MJ, Prevost AT. Dietary patterns and their associations with demographic, lifestyle and health variables in a random sample of British adults. British Journal of Nutrition 1996; 76: 17-30.

30 Slattery ML, Boucher KM, Caan BJ, Potter JD, Ma KN. Eating patterns and risk of colon cancer. American Journal of Epidemiology 1998; 148: 4-16.

31 Menotti A, Kromhout D, Blackburn H, Fidanza F, Buzina R, Nissinen A. Food intake patterns and 25-year mortality from coronary heart disease: cross-cultural correlations in the Seven Countries Study. The Seven Countries Study Research Group. European Journal of Epidemiology 1999; 15: 507-15.

32 Hu FB, Rimm EB, Stampfer MJ, Ascherio A, Spiegelman D, Willett WC. Prospective study of major dietary patterns and risk of coronary heart disease in men. American Journal of Clinical Nutrition 2000; 72: 912-21.

33 Osler M, Heitmann BL, Gerdes LU, Jørgensen LM, Schroll M. Dietary patterns and mortality in Danish men and women: a prospective observational study. British Journal of Nutrition 2001; 85: 219-25.

34 Osler M, Helms Andreasen A, Heitmann B, Hoidrup S, Gerdes U, Morch Jorgensen L, et al. Food intake patterns and risk of coronary heart disease: a prospective cohort study examining the use of traditional scoring techniques. European Journal of Clinical Nutrition 2002; 56: 568-74.

35 Terry P, Hu FB, Hansen H, Wolk A. Prospective study of major dietary patterns and colorectal cancer risk in women. American Journal of Epidemiology 2001; 154: 1143-9.

36 Fung TT, Willett WC, Stampfer MJ, Manson JE, Hu FB. Dietary patterns and the risk of coronary heart disease in women. Archives of Internal Medicine 2001; 161: 1857-62.

37 van Dam RM, Rimm EB, Willett WC, Stampfer MJ, Hu FB. Dietary patterns and risk for type 2 diabetes mellitus in US men. Annals of Internal Medicine 2002; 136: 201-9.

38 Martinez ME, Marshall JR, Sechrest L. Invited commentary: Factor analysis and the search for objectivity. American Journal of Epidemiology 1998; 148: 17-9.

39 Riboli E, Hunt KJ, Slimani N, Ferrari P, Norat T, Fahey M, et al. European Prospective Investigation into Cancer and Nutrition (EPIC): study populations and data collection. Public Health Nutrition 2002; 5: 1113-24.

40 Slimani N, Kaaks R, Ferrari P, Casagrande C, Clavel-Chapelon F, Lotze G, et al. European Prospective 
Investigation into Cancer and Nutrition (EPIC) calibration study: rationale, design and population characteristics. Public Health Nutrition 2002; 5: 1125-45.

41 Margetts BM, Pietinen P. European Prospective Investigation into Cancer and Nutrition: validity studies on dietary assessment methods. International Journal of Epidemiology 1997; 26(Suppl. 1): S1-5.

42 Willett WC. Diet and coronary heart disease. In: Willett WC, ed. Nutritional Epidemiology. 2nd ed. New York: Oxford University Press, 1998; 414-66.

43 James WPT, Schofield EC. Human Energy Requirements. A Manual for Planners and Nutritionists. Oxford: Oxford University Press, 1990.

44 Marmot MG. Alcohol and coronary heart disease. International Journal of Epidemiology 2001; 30: 724-9.

45 Britton A, Marmot M. Different measures of alcohol consumption and risk of coronary heart disease and allcause mortality: 11-year follow-up of the Whitehall II Cohort Study. Addiction 2004; 99: 109-16.

46 World Cancer Research Fund (WCRF)/American Institute for Cancer Prevention (AICR). Food, Nutrition and the Prevention of Cancer: A Global Perspective. Washington, DC: WCFR/AICR, 1997.

47 Singh PN, Sabate J, Fraser GE. Does low meat consumption increase life expectancy in humans? American Journal of Clinical Nutrition 2003; 78(3 Suppl.): $526 \mathrm{~S}-32 \mathrm{~S}$

48 Kelemen LE, Kushi LH, Jacobs DR Jr, Cerhan JR. Associations of dietary protein with disease and mortality in a prospective study of postmenopausal women. American Journal of Epidemiology 2005; 161: 239-49.

49 Trichopoulou A, Naska A, Orfanos P, Trichopoulos D. Mediterranean diet in relation to body mass index and waistto-hip ratio: the Greek European Prospective Investigation into Cancer and Nutrition Study. American Journal of Clinical Nutrition 2005; 82: 935-40.

50 Panagiotakos DB, Arapi S, Pitsavos C, Antonoulas A, Mantas $\mathrm{Y}$, Zombolos S, et al. The relationship between adherence to the Mediterranean diet and the severity and short-term prognosis of acute coronary syndromes (ACS): The Greek Study of ACS (The GREECS). Nutrition 2006; 22: $722-30$.

51 Huijbregts PP, Feskens EJ, Kromhout D. Dietary patterns and cardiovascular risk factors in elderly men: the Zutphen Elderly Study. International Journal of Epidemiology 1995; 24: 313-20.

52 Tucker KL, Chen H, Hannan MT, Cupples LA, Wilson PW, Felson D, et al. Bone mineral density and dietary patterns in older adults: the Framingham Osteoporosis Study. American Journal of Clinical Nutrition 2002; 76: 245-52.

53 Diehr P, Beresford SA. The relation of dietary patterns to future survival, health, and cardiovascular events in older adults. Journal of Clinical Epidemiology 2003; 56: 1224-35.

54 Williams DE, Prevost AT, Whichelow MJ, Cox BD, Day NE, Wareham NJ. A cross-sectional study of dietary patterns with glucose intolerance and other features of the metabolic syndrome. British Journal of Nutrition 2000; 83: 257-66. 